\title{
Metabolism in mesopelagic and bathypelagic copepods: Reply to Childress et al. (2008)
}

\author{
Tsutomu Ikeda* \\ Plankton laboratory, Graduate School of Fisheries Sciences, Hokkaido University, Minato-cho, Hakodate, 041-8611, Japan
}

Present address: 16-3-1001 Toyokawa-cho, Hakodate, 040-0065, Japan

\begin{abstract}
In reply to the Comment by Childress et al. (2008; Mar Ecol Prog Ser 373:187-191), a rationale is given for the use of $\mathrm{N}$-specific respiration data (instead of live-mass specific respiration data), life stage/sex structured data (instead of species structured data), capture depth (instead of minimum depth of occurrence, MDO) and respirometry design including enzyme assay of electron transfer system (ETS) (instead of citrate synthase [CS] assay), low oxygen seawater from the capture depth of the copepods (instead of oxygen enriched seawater) and density effect in the experiment of Ikeda et al. (2006; Mar Ecol Prog Ser 322:199-211). These results, combined with recent reports on chemical composition and RNA:DNA ratios, continue to support the conclusion of reduced respiration in deeper-living copepods. The gap between the species-based wet-mass specific respirationMDO approach promoted by Childress et al. (2008) and the individual-based N-specific respirationcapture depth approach of Ikeda et al. (2006) is due to the different philosophical outlooks of the 2 research groups. One is based on the highly focused view of animal physiology, the other is based on the broad view of biological oceanography that incorporates all aspects of biology.
\end{abstract}

KEY WORDS: Copepods · Respiration · ETS · Mesopelagic · Bathypelagic · 'Visual interactions' hypothesis

Childress et al. (2008) question the validity of the conclusion in Ikeda et al. (2006a) that the respiration (i.e. oxygen consumption) rate of pelagic copepods decreases with habitat depth, instead of remaining constant with respect to habitat depth as postulated by the 'visual interactions' hypothesis of Childress \& Mickel (1985). Since copepods are the most dominant component of mesozooplankton communities in the world ocean and play integral roles in biogeochemical cycles of carbon and other elements in the ocean interior, it is urgent to resolve whether or not their respiration rates are influenced by depth. Once this issue is resolved, it will become possible to develop a global-bathymetric model of copepod respiration (Ikeda et al. 2007a).
Live mass versus $\mathbf{N}$ content as a basis of rigorous interspecific comparison of metabolism

Respiration data can be expressed relative to dry weight, carbon (C) or nitrogen (N). Most zooplankton organisms (including copepods studied by Ikeda et al [2006a]) are small in size (a few $\mathrm{mm}$ ) and have fragile bodies with a complex structure, which makes it difficult to drain water quickly from their body surfaces for accurate weighing (wet weight), especially during experiments at sea. Wet weight has routinely been determined in fishes and large crustaceans, which do not pose the technical problems associated with handling small, live zooplankton specimens. However, animal size is not the only reason for the use of $\mathrm{N}$ mass in Ikeda et al. (2006a). 
When body constituents such as water, organic matter and inorganic matter are at constant levels between animals, the results of comparisons should be the same. However, body constituents may change greatly, depending on the evolution and habitat of animals (Ivleva 1980, Ikeda 1985). As a typical example, a comparison of respiration rates in krill Euphausia superba and salps Salpa thompsoni and Ihlea racovitzai of equivalent body mass at the same temperature yields different results, based on body-mass units; the rate in salps is greater than that in krill by a multiplication factor of 17 based on wet weight, 4 based on dry weight, and 0.8 based on $\mathrm{N}$ or C (Ikeda \& Mitchell 1982). In earlier studies, comparing the metabolism of diverse animal phyla, Zeuthen $(1947,1953)$ also noticed that $\mathrm{N}$-specific respiration rates reduced differences between phyla, compared with live massspecific respiration rates. Proteins are of prime importance for living systems, as they include the enzymes whose activity and concentration determine metabolic rates. Preferential use of $\mathrm{N}$ to standardize zooplankton metabolic data reflects that the $\mathrm{N}$ pool in zooplankton is mainly from protein (68 to $84 \%$ for crustacean plankton, cf. Ventura 2006). In addition, $\mathrm{N}$ can be determined accurately with smaller samples (1 mg dry weight) by means of an elemental analyzer. Carbon has been used as the common unit of biomass in the study of trophodynamics (Postel et al. 2000), but it may introduce a bias in comparing the metabolism of zooplanktonic organisms having or lacking stored lipids (as energy reserve). As far as the copepods studied by Ikeda et al. (2006a) are concerned, their N-specific respiration data can be converted to wet weight-specific respiration data by using $\mathrm{N}$ composition data of the copepods (Ikeda et al. 2006b). According to Ikeda et al. (2006b), water content (\% of wet weight) of copepods does not change with depth, though $\mathrm{N}$ composition ( $\%$ of dry weight) declines slightly with increasing depth; therefore the conclusion of lowered respiration rates with depth in Ikeda et al. (2006a) remains unchanged if $\mathrm{N}$-specific rates are converted to wet weight-specific respiration rates.

Metabolic comparison of animals with dissimilar body mass and body structure, and from different temperature regimes, requires a common scaling exponent (b for the equation $R=\mathrm{a} M^{\mathrm{b}}$, where $R$ is respiration rate, $M$ is body mass, and a is a constant), common temperature coefficient $\left(Q_{10}\right.$ or $\mathrm{E}_{\mathrm{a}}$ in Arrhenius plots), and common body mass unit ( $\mathrm{N}$ instead of live weight) (Ikeda et al. 2006a). Prior to the study on copepods (Ikeda et al. 2006a), N-specific metabolic rates were used to test presence or absence of cold adaptation in Antarctic zooplankton (Ikeda 1989) and reduced metabolic rates in mesopelagic crustaceans (decapods, an amphipod, a mysid, a euphausiid and an ostracod) in Antarctic waters (Ikeda 1988). Childress et al. (2008) criticize the use of $\mathrm{N}$-specific respiration rates, but Childress (1995) cited the results of Ikeda (1988) as evidence in support of the 'visual interactions' hypothesis.

\section{Defining habitat depth and treatment of respiration data}

Minimum depth of occurrence (MDO) as defined by Childress et al. (2008) is the shallowest depth below which $90 \%$ of the individuals in a population live. Since the information about vertical distribution of each species is extremely limited, Childress et al. (2008) established species-specific MDO based on data from the literature and their own observations. Because of this, MDO is not related to the actual depth of capture of animals on which respiration rate is determined. Regardless of the evolutionary and ecological rationale, MDO is not an appropriate reference for respiration data divided into life stage and sex - as done by Ikeda et al. (2006a) - because of possible ontogenetic vertical migration behavior in some mesopelagic/ bathypelagic copepods. Young copepodids of some Paraeuchaeta species ascend with development. The vertical distance spanned during their life cycle has been estimated to be as large as $1000 \mathrm{~m}$ (Yamaguchi et al. 2004). Additionally, a serious problem inherent with using MDO is that the respiration-MDO relationship cannot be used directly for the estimation of respiration rate of any pelagic animals collected from a given depth without identification to species and re-adjusting its MDO beforehand. The problem is further confounded if MDO of a given species varies with region.

In contrast, Ikeda et al. (2006a) defined habitat depth of copepods as capture depth (mid-sampling depth intervals). In this way, habitat depths of copepods from mesopelagic (500 to $1000 \mathrm{~m}$ ), upper-bathypelagic (1000 to $2000 \mathrm{~m}$ ) and lower bathypelagic zones (2000 to $3000 \mathrm{~m}$ ) were designated as 750, 1500 and $2500 \mathrm{~m}$, respectively. The $\mathrm{N}$-specific relationship between respiration and capture depth of copepods in Ikeda et al. (2006a) can be used directly for the estimation of respiration rate of any copepods from a given depth by knowing its $\mathrm{N}$ mass only, without species identification. It should be noted that the choice of MDO by Childress et al. (2008) or capture depth by Ikeda et al. (2006a) for defining habitat depths does not affect the conclusion if copepod respiration rates are constant with depth as predicted from the 'visual interactions' hypothesis.

Unlike the species-specific respiration data (e.g. single species represented by single respiration data) of Childress et al. (2008), the copepod respiration data 
of Ikeda et al. (2006a), which were classified into species and then life stage/sex, represent individuals from the bathymetric zones in which they were captured. In this way, some copepods occurred across 2 or 3 bathymetric zones. This was done because the information about ontogenetic migration, life cycle and population genetics of all deep-sea copepod species is extremely limited (Braga et al. 1999, Yamaguchi \& Ikeda 2000a,b, Bucklin et al. 2003, Yamaguchi et al. 2004). Furthermore, metabolic rates in copepods and zooplankton are generally governed by body mass and habitat temperature, not by species identity (Ikeda 1985, Ikeda et al. 2001). In Ikeda et al. (2006a), 2 types of statistical test were made on the pooled respiration data. (1) Stepwise multiple regression (Sokal \& Rohlf 1995) was applied to reveal significantly higher metabolic rates in mesopelagic copepods, as compared to the rates in upper and lower bathypelagic copepods; stage/sex, feeding type and presence/absence of myelinated sheath were also analyzed. (2) Regression analysis based on the 4 bathypelagic depth levels was used to reveal the rapid decline of the respiration rate with increasing habitat depth, which is found when the epipelagic data of Arctic/Antarctic copepods are considered.

\section{Electron transfer system as a proxy for metabolic rates}

Childress et al. (2008) point out that Ikeda et al. (2006a) used an enzyme assay of the electron transfer system (ETS), not citrate synthase (CS), as a proxy for metabolic rate. CS was used by Childress et al. (2008) and their colleagues to control for artefacts due to damage to the specimens or due to unrealistic levels of activity of various pelagic animals incurred during the process of retrieval of animals from depth. Childress et al. (2008) state that ETS is not an exact predictor of metabolic rate. Activities of ETS, CS and other enzymes of intermediary metabolism - e.g. lactate dehydrogenase (LDH), pyruvate kinase (PK) and malate dehydrogenase (MDH); cf. review by Ikeda et al. (2000) - are measured under saturating conditions of substrates and cofactors so that they estimate potential respiration rates $\left(\mathrm{V}_{\max }\right.$ of the MichaelisMenten equation). The choice of enzyme usually reflects a compromise between logistic feasibility and resource availability. However, Ikeda et al. (2006a) did not use CS because this enzyme is not useful for analysis in copepods: 'we are unable to show that CS was significantly correlated with oxygen consumption in these copepods. This was disappointing' (Thuesen et al. 1998, p. 105). Moreover, correlation between respiration and CS is highly variable across some zooplankton groups $\left(\mathrm{r}^{2}=0.88\right.$ for chaetognaths in Thuesen \& Childress 1993a; $\mathrm{r}^{2}=0.34$ for pelagic worms in Thuesen \& Childress 1993b; $\mathrm{r}^{2}=0.10$ to 0.40 for medusae in Thuesen \& Childress 1994). Compared with the limited use of CS and other enzymes of intermediary metabolism in biological oceanography, ETS has been used as a proxy for metabolism of diverse marine organisms including deep-sea zooplankton (Packard 1985, Koppelmann \& Weikert 1999, Hernández-León \& Ikeda 2005a, Packard \& Gómez 2008). The effect of hydrostatic pressure on ETS activities of crustacean plankton is insignificant, at least up to $265 \mathrm{~atm}$ (King \& Packard 1975a).

Application of enzymatic methods to estimate metabolic rates of zooplankton relies on a constant or predictable relationship between the two. Studies evaluating the relationship for CS and other enzymes of intermediary metabolism in zooplankton have lagged far behind studies with ETS. Since the review of Mayzaud (1986) ${ }^{\mathbf{1}}$, new data on the ETS: $R$ ratio and its variability have been collected. In particular, Hernández-León \& Gómez (1996) analyzed 202 ETS:R ratio data from zooplankton and showed that the principal mode is close to the theoretical ratio (i.e. 2). Potential sources of error for ETS: $R$ ratios that have been investigated include growth conditions of organisms, body size, feeding condition, mismatch between metabolic rate and enzyme activity, and calibration design (Ikeda et al. 2000, Hernández-León \& Ikeda 2005b) ${ }^{2}$.

Childress et al. (2008) argue that the ETS: $R$ calibration procedure of King \& Packard (1975b) for zooplankton is not adequate, and the plot of $\mathrm{N}$-specific ETS and N-specific respiration rate of deep-sea copepods in Ikeda et al. (2006a) is not valid. In my view, calibration by plotting total ETS and total $R$ (instead of mass-specific ETS and mass-specific $R$ ) by King \& Packard (1976) is a sensible approach, as their measurements of respiration and ETS were made successively on the same batch of zooplankton specimens. We used ETS activity to validate $R$ in deep-sea copepods by demonstrating (1) a depth-related decline $($ ETS $=5.403-0.445 \ln$ Depth, $r=0.966, p<0.05 ;$ Ikeda et al. 2006a, p. 205) and (2) that measured data are close to the theoretical value of 2 , by comparing $R$ values at different depth strata (Ikeda et al. 2006a, their Fig. 3) In this Fig. 3, the vertical and horizontal error

\footnotetext{
1ETS:R (respiration) ratios of Ikeda \& Skjoldal (1980) and Ikeda \& Hing Fay (1981) are incorrectly referred to as $R$ :ETS ratios in Mayzaud (1986, p. 248)

2Since early ETS activities were measured with a technique that is much less sensitive than recent methods, the intercomparison study of Christensen \& Packard (1979) must be considered in comparisons of data obtained by old and new methods
} 
bars across the means are SD of ETS and $R$, respectively, not SD of ETS: $R$ ratios. As mentioned clearly in Ikeda et al. (2006a), the anomalous ETS: $R$ ratio for epipelagic data indicates that it is invalid to compare copepods living in Arctic/Antarctic waters ( $R$ data) with those living in the western subarctic Pacific (ETS data).

\section{Methods for measuring respiration rate $R$}

Childress et al. (2008) argue that the experimental conditions (number of copepods per container) and the use of low oxygen in seawater (oxygen level at capture depth of copepods) are potential sources of error in Ikeda et al. (2006a); the implications of both aspects for measuring metabolic rates of marine zooplankton have been discussed in Ikeda et al. (2000).

Briefly, the sealed-chamber method adopted by Ikeda et al. (2006a) is the traditional method for determining respiration and/or excretion in zooplankton. Oxygen consumed and/or excreta (N, P) accumulated over time are measured in sealed containers with and without (control) animals. The use of single specimens or batches per container depends on the number of available individuals for determination of respiration or excretion, or both. Potential effects of container size/density questioned by Childress et al. (2008) are one of several other sources of possible error examined since the early studies of Marshall \& Orr (1958). Container size and crowding determine the volume available per individual (i.e. density); container size largely determines interactions with the container wall, and crowding influences interactions between individuals. Childress et al. (2008) speculate that the use of batches in Ikeda et al. (2001: epipelagic copepods, 5 to 20 ind. per $300 \mathrm{ml}$ container) yielded higher respiration rates, compared with the use of single specimens in Ikeda et al. (2006a: mesopelagic/bathypelagic copepods, 1 ind. per 40 to $70 \mathrm{ml}$ container), but these effects are variable with no consistent trend (cf. Ikeda et al. 2000). Therefore, the differences between the 2 experimental designs are unlikely to cause consistently lower rates in Ikeda et al. (2006a), as compared with Ikeda et al. (2001).

Childress et al. (2008) claim that the low respiration rates of deep-sea copepods in Ikeda et al. (2006a) were due to the use of low oxygen seawater (1.6 to $2.0 \mathrm{mlO}_{2}$ $\mathrm{l}^{-1}$ ) from the deep habitat of the copepods. For realistic estimation of respiration in deep-sea copepods, it is important to consider oxygen saturation along with temperature and other in situ environmental parameters. In Ikeda et al. (2006a), the oxygen concentration at the end of most experiments was $>1 \mathrm{ml} \mathrm{l}^{-1}$ ( $=21 \mathrm{~mm} \mathrm{Hg}$, or $3 \mathrm{KPa})$, which is well above the critical

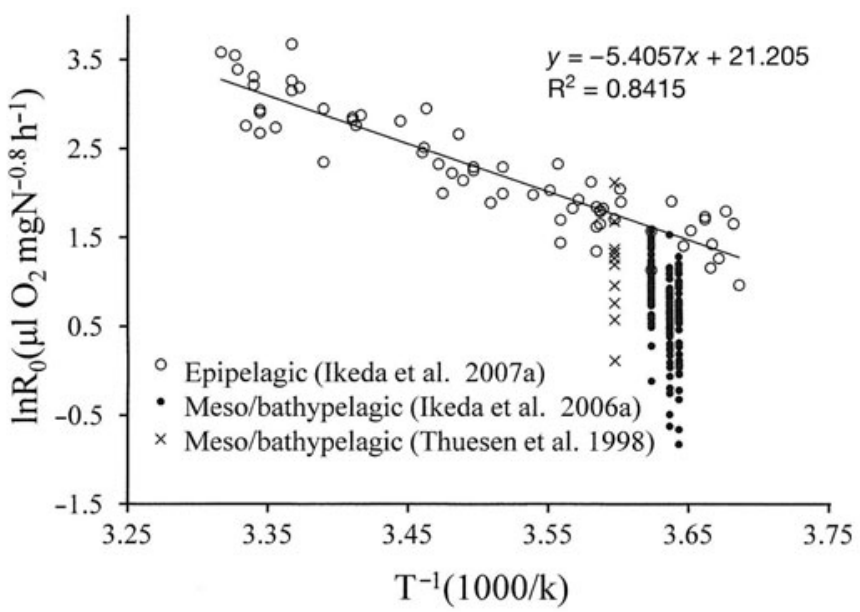

Fig. 1. Relationship between the respiration rate of copepods standardized to a body size of $1 \mathrm{mg}$ body $\mathrm{N}\left(\mathrm{R}_{\mathrm{o}}\right)$ and inverse temperature $\left(\mathrm{T}^{-1}\right)$ (Arrhenius plot); regression fitted only for epipelagic copepod data. Respiration rates of mesopelagic/ bathypelagic respiration data of Ikeda et al. (2006a) and Thuesen et al. (1998) are significantly lower than the rates of epipelagic copepods (Mann-Whitney $U$-test, $p<0.001$ for both cases), but differences between Ikeda et al. (2006a) and Thuesen et al. (1998) within mesopelagic/bathypelagic copepods are not significant ( $U$-test, $\mathrm{p}=0.18$ ); all respiration data $\left(\mathrm{R}_{\mathrm{o}}\right)$ were adjusted to the rate at $5^{\circ} \mathrm{C}$ along the slope of the regression line. Data of Thuesen et al. (1998) with complete sets of respiration rate, MDO (>500 m) and protein content were selected and protein content was converted to $\mathrm{N}$ by multiplying by 0.2 (modified from Ikeda et al. 2007a)

oxygen pressure $\left(\mathrm{P}_{\mathrm{c}}\right)$ of ca. $10 \mathrm{mmHg}$ in the 3 deep-sea copepods (Childress 1975) and that of midwater crustaceans, fishes and cephalopods $(0.4 \mathrm{kPa}$; Childress \& Seibel 1998). Moreover, the respiration data of mesopelagic and bathypelagic copepods in the western subarctic Pacific (Ikeda et al. 2006a), where oxygen concentrations are relatively high, and those off California (Thuesen et al. 1998), where they are lower, do not differ significantly ( $U$-test, $\mathrm{p}=0.18$ ) when the latter are converted to N-specific data (Fig. 1).

\section{Conclusions}

Contrary to the assertion of Childress et al. (2008) that the lower respiration rates of mesopelagic and bathypelagic copepods reported by Ikeda et al. (2006a) are flawed due to 4 principal errors, the validity of the latter study (Ikeda et al. 2006a) is largely supported by the work of Childress, Seibel and Thuesen (CS activity, $\mathrm{P}_{\mathrm{c}}$ and respiration data in Fig. 1). Subsequent studies on copepods from the epi-, meso-, bathy- and abyssopelagic zones $(<5000 \mathrm{~m})$ of the western subarctic Pacific demonstrated that deeper living copepods are characterized by lower $\mathrm{N}$ content (i.e. reduction in 
muscle mass; Ikeda et al. 2006b) and RNA:DNA ratios (i.e. lower protein synthetic activity; Ikeda et al. $2007 b)$, which are consistent with the conclusion of Ikeda et al. (2006a).

The gap between the species-based wet-mass specific respiration-MDO approach promoted by Childress et al. (2008) and the individual-based N-specific respiration-capture depth approach of Ikeda et al. (2006a) appears too deep to be easily bridged. The gap is due to the different philosophical outlooks of the 2 research groups. One is based on the highly focused view of animal physiology, the other is based on the broad view of biological oceanography that incorporates all aspects of biology. In spite of this problem, the results of Ikeda et al. (2006a) on copepods can be used to test whether or not the 'visual interactions' hypothesis generally holds true for the diverse zooplankton groups distributed throughout the oceans of the world.

All raw data of the metabolic rates of copepods from the deep-sea in Ikeda et al. (2006a) and Ikeda et al. (2007a) are available as appendices at www.intres.com/articles/suppl/m322p199_app.pdf and www. int-res.com/articles/suppl/m339p215_app.pdf, respectively, and the data on copepods and other zooplankton from the epipelagic zones of the world oceans in the Hokkaido University Collection of Scholarly and Academic Papers (HUSCUP, http://hdl.handle.net/ 2115/33838) and EUROCEANS Vital Rates databasezooplankton can be found in: http://lgmacweb.env. uea.ac.uk/green_ocean/data/index.shtml. All data are available for free download.

Acknowledgements. This manuscript benefited from constructive comments provided by T. T. Packard.

\section{LITERATURE CITED}

Braga E, Zardoya R, Meyer A, Yen J (1999) Mitochondrial and nuclear rRNA based copepod phylogeny with emphasis on the Euchaetidae (Calanoida). Mar Biol 133:79-90

Bucklin A, Frost BW, Bradford-Grieve J, Allen LD, Copley NJ (2003) Molecular systematic and phylogenetic assessment of 34 calanoid copepod species of the Calanidae and Clausocalanidae. Mar Biol 142:333-343

Childress JJ (1975) The respiratory rates of midwater crustaceans as a function of depth occurrence and relation to the oxygen minimum layer off Southern California. Comp Biochem Physiol A 50:787-799

Childress JJ (1995) Are there physiological and biochemical adaptations of metabolism in deep-sea animals? Trends Ecol Evol 10:30-36

Childress JJ, Mickel TJ (1985) Metabolic rates of animals from the hydrothermal vents and other deep-sea habitats. Bull Biol Soc Wash 6:249-260

> Childress JJ, Seibel BA (1998) Life at stable low oxygen levels: adaptations of animals to oceanic oxygen minimum layers. J Exp Biol 201:1223-1232

Childress JJ, Seibel BA, Thuesen EV (2008) N-specific metabolic data are not relevant to the 'visual interactions' hypothesis concerning the depth-related declines in metabolic rates: Comment on Ikeda et al. (2006). Mar Ecol Prog Ser 373:187-191

Christensen JP, Packard TT (1979) Respiratory electron transport activities in plankton: Comparison of methods. Limnol Oceanogr 24:576-583

Hernández-León S, Gómez M (1996) Factors affecting the respiration/ETS ratio in marine zooplankton. J Plankton Res 18:239-255

> Hernández-León S, Ikeda T (2005a) A global assessment of mesozooplankton respiration in the ocean. J Plankton Res $27: 153-158$

Hernández-León S, Ikeda T (2005b) Zooplankton respiration. In: del Giorgio PA, Williams PJleB (eds) Respiration in aquatic ecosystems. Oxford University Press, New York, p 57-82

Ikeda T (1985) Metabolic rates of epipelagic marine zooplankton as a function of body mass and temperature. Mar Biol 85:1-44

> Ikeda T (1988) Metabolism and chemical composition of crustaceans from the Antarctic mesopelagic zone. DeepSea Res 35:1991-2002

Ikeda T (1989) Are antarctic zooplankton metabolically more cold-adapted than arctic zooplankton? An intra-generic comparison of oxygen consumption rates. J Plankton Res 11:619-624

Ikeda T, Hing Fay E (1981) The metabolic activity of zooplankton from the Antarctic Ocean. Aust J Mar Freshw Res 32:921-930

Ikeda T, Mitchell AW (1982) Oxygen uptake, ammonia excretion and phosphate excretion by krill and other Antarctic zooplankton in relation to their body size and chemical composition. Mar Biol 71:283-298

Ikeda T, Skjoldal R (1980) The effect of laboratory conditions on the extrapolation of experimental measurements to the ecology of marine zooplankton. Vl. Changes in physiological activities and biochemical components of Acetes sibogae australis and Acartia australis after capture. Mar Biol 58:285-293

Ikeda T, Torres JJ, Hernández-León S, Geiger SP (2000) Metabolism. In: Harris RP, et al. (eds) ICES zooplankton methodology manual. Academic Press, San Diego, CA, p 455-532

Ikeda T, Kanno Y, Ozaki K, Shinada A (2001) Metabolic rates of epipelagic marine copepods as a function of body mass and temperature. Mar Biol 139:587-596

> Ikeda T, Sano F, Yamaguchi A, Matsuishi T (2006a) Metabolism of mesopelagic and bathypelagic copepods in the western North Pacific Ocean. Mar Ecol Prog Ser 322: $199-211$

Ikeda T, Yamaguchi A, Matsuishi T (2006b) Chemical composition and energy content of deep-sea calanoid copepods in the Western North Pacific Ocean. Deep-Sea Res I 53: 1791-1809

Ikeda T, Sano F, Yamaguchi A (2007a) Respiration in marine pelagic copepods: a global-bathymetric model. Mar Ecol Prog Ser 339:215-219

Ikeda T, Sano F, Yamaguchi A, Matsuishi T (2007b) RNA:DNA ratios of calanoid copepods from the epipelagic through abyssopelagic zones of the North Pacific Ocean. Aquat Biol 1:99-108

Ivleva IV (1980) The dependence of crustacean respiration rate on body mass and habitat temperature. Int Rev Gesamten Hydrobiol 65:1-47

King FD, Packard TT (1975a) The effect of hydrostatic pressure on respiratory electron transport system activity in 
marine zooplankton. Deep-Sea Res 22:99-105

King FD, Packard TT (1975b) Respiration and the activity of the respiratory electron transport system in marine zooplankton. Limnol Oceanogr 20:849-854

Koppelmann R, Weikert H (1999) Temporal changes of deepsea mesozooplankton abundance in the temperate NE Atlantic and estimates of the carbon budget. Mar Ecol Prog Ser 179:27-40

Marshall SM, Orr AP (1958) Some uses of antibiotics in physiological experiments in sea water. J Mar Res 17: 341-346

Mayzaud P (1986) Enzymatic measurements of metabolic processes concerned with respiration and ammonia excretion. In: Corner EDS, O'Hara SCM (eds) The biological chemistry of copepods. Oxford University Press, Oxford, p 226-259

Packard TT (1985) Oxygen consumption in the ocean: measuring and mapping with enzyme analysis. In: Zirino A (ed) Mapping strategies in chemical oceanography. Adv Chem Ser 209:177-209

Packard TT, Gómez M (2008) Exploring a first-principlesbased model for zooplankton respiration. ICES J Mar Sci 65:371-378

Postel L, Fock H, Hagen W (2000) Biomass and abundance. In: Harris RP, et al. (eds) ICES zooplankton methodology manual. Academic Press, San Diego, CA, p 83-192

Sokal RR, Rohlf FJ (1995) Biometry. Freeman, New York

Thuesen EV, Childress JJ (1993a) Enzymatic activities and metabolic rates of pelagic chaetognaths: lack of depthrelated declines. Limnol Oceanogr 38:935-948

Thuesen EV, Childress JJ (1993b) Metabolic rates, enzyme activities and chemical compositon of some deep-sea

Editorial responsibility: Matthias Seaman,

Oldendorf/Luhe, Germany pelagic worms, particularly Nectonemertes mirabilis (Nemertea; Hoplonemertinea) and Poeobius meseres (Annelida; Polychaeta). Deep-Sea Res I 40:937-951

> Thuesen EV, Childress JJ (1994) Oxygen consumption rates and metabolic enzyme activities of oceanic California medusae in relation to body size and habitat depth. Biol Bull 187:84-98

Thuesen EV, Miller CB, Childress JJ (1998) Ecophysiological interpretation of oxygen consumption rates and enzymatic activities of deep-sea copepods. Mar Ecol Prog Ser 168: 95-107

Ventura M (2006) Linking biochemical and elemental composition in freshwater and marine crustacean zooplankton. Mar Ecol Prog Ser 327:233-246

Yamaguchi A, Ikeda T (2000a) Vertical distribution, life cycle and body allometry of two oceanic calanoid copepods (Pleuromamma scutullata and Heterorhabdus tanneri) in the Oyashio region, western North Pacific Ocean. J Plankton Res 22:29-46

> Yamaguchi A, Ikeda T (2000b) Vertical distribution, life cycle and developmental characteristics of the mesopelagic calanoid copepod Gaidius variabilis (Aetideidae) in the Oyashio region, western North Pacific Ocean. Mar Biol 137:99-109

Yamaguchi A, Ikeda T, Watanabe Y, Ishizaka J (2004) Vertical distribution patterns of pelagic copepods as viewed from the predation pressure hypothesis. Zool Stud 43:475-485

Zeuthen E (1947) Body size and metabolic rate in the animal kingdom with special regard to the marine microfauna. C r Trav Lab Carlsberg (S6r chim) 26:17-161

Zeuthen E (1953) Oxygen uptake as related to body size in organisms. Q Rev Biol 28:1-12

Submitted: November 24, 2008; Accepted: Novermber 26, 2008 Proofs received from author(s): December 9, 2008 